\title{
Urinary tract infections and antibiotic susceptibility among the patients attending B \& D hospital of Lalitpur, Nepal
}

\author{
Yadav Prasad Joshi', Shreejeet Shrestha ${ }^{2}$, Russell Kabir ${ }^{3}$, Anita Thapa ${ }^{4}$, Parbati Upreti ${ }^{5}$, \\ Sanjit Shrestha ${ }^{6}$ \\ ${ }^{1} P h D$ Researcher, Department of Social and Preventive Medicine, School of Medicine, Sungkyunkwan University, The \\ Republic of Korea, ${ }^{2}$ Principal, Asian College for Advanced Studies, Lalitpur, Nepal, ${ }^{3}$ Senior Lecturer, Department for \\ Allied and Public Health, Anglia Ruskin University, Chelmsford, UK, ${ }^{4}$ Medical Officer, Department of Gynaecology and \\ Obstetrics, KIST Medical College \& Teaching Hospital, Imadol, ${ }^{5}$ Research Officer, Global Institute for Policy Studies \\ (GIPS), Kathmandu, ${ }^{6}$ Microbiologist, Department of Pathology, B \& B Hospital, Lalitpur, Nepal
}

\section{A B S T R A C T}

Background: Urinary tract infection (UTI) is the most common bacterial infections in humans and serious health problem in many parts of the world. It has become more complicated in treatment due to different pathogens and increasing resistant to antimicrobial agents. Aims and Objectives: This study aims to investigate the prevalence of urinary tract infection and antibiotic susceptibility patterns of pathogens among the patients attending in $B \& B$ hospital Nepal. Materials and Methods: A hospital based cross sectional study was conducted in between April 2010 to March 2011. Urine samples were collected from clinically suspected patients and tested bacteriologically using standard procedures. Antimicrobial susceptibility test was performed for isolated pathogen using the Kirby-Bauer disk diffusion method according to Clinical and Laboratory Standards Institute guidelines. Results: Out of 1260 examined specimens $25.24 \%$ were positive and majority $61.64 \%$ were females. The most common pathogens isolated were Escherichia coli $(66.67 \%)$, Enterococcus $(7.55 \%)$ and Staphylococcus $(6.60 \%)$. The drug resistant among the positive cases were reported. The highest resistant of positive cases was found with Cefexime $(87.88 \%)$ and Enterococcus with Ampicillin (66.67\%) and Staphyllococcus with Cloxacillin (66.67\%). The highest susceptibility was for Vancomycin and Ampicillin i.e. 33.33\% in each. Conclusion: The findings showed that $E$. coli isolates were the predominant pathogen and the presence of bacterial isolates with very high resistance to the commonly prescribed drugs. As drug resistance among bacterial pathogens is an evolving process and serious issue. Therefore, routine surveillance and monitoring studies should be conducted to provide physicians knowledge on the updated and most effective empirical treatment of UTIs.

Access this article online

Website:

http://nepjol.info/index.php/AJMS

DOI: 10.3126/ajms.v7i5.14908

E-ISSN: 2091-0576

P-ISSN: $2467-9100$

Key words: Urinary tract infection, Antibiotic susceptibility, Kathmandu, Nepal

\section{INTRODUCTION}

Urinary Tract Infection (UTI) is an infection caused by the presence and growth of microorganisms anywhere in the urinary tract. ${ }^{1}$ UTIs are among the most common bacterial infections in humans both in the community and hospital settings. These infections are found in all age and usually required urgent treatment., ${ }^{2,3}$ Among the sexes, females are however believed to be more affected than males except at the extremes of life. ${ }^{4}$

UTI is a serious health problem affecting millions of people each year and is the leading cause of gram-negative bacteriaemia. ${ }^{5}$ Among hospital patients, it has become the most common hospital acquired infection, accounting more than $35 \%$ of nosocomial infections, and it is the second most 
common cause of bacteraemia. ${ }^{4} \mathrm{UTI}$ accounts for a significant part of the work load in clinical microbiology laboratories. The most common causative pathogens associated with UTIs are E coli (80\%) and $S$ saprophyticus (5\% to $15 \%))^{4,6,}$ 7 The majority of infections in UTIs are uncomplicated but when patients have functional, metabolic or structural abnormalities the infections are considered complicated. The etiology of complicated UTI is more diverse and frequently polymicrobial in nature. Specific host factors, such as the extremes of age, pregnancy, diabetes, catheterization, or spinal cord injuries, can impact on etiology. ${ }^{6}$

Most of the UTI in the hospital setting are initially treated empirically based on the frequency of potential pathogens, local antimicrobial resistance rates and illness severity. The use of inappropriate empirical therapy was found to be a predictor of mortality in patients who had bacteraemia originating from a urinary tract source. ${ }^{8}$ The establishment of worldwide antimicrobial resistance surveillance systems seems to be an important step in detecting the emergence of resistance patterns, helping in the selection of the most efficacious empirical therapy at the local level and supporting the implementation of preventive measures. ${ }^{9}$

In Nepal and other developing countries, UTI is the most common bacterial infection causing illness mostly in females due to illiteracy, unhygienic conditions and lack of proper toilet facilities. They are always vulnerable to infections by various organisms. ${ }^{10}$ Microbial resistance to nearly all classes of antimicrobials continues to rise despite increasing awareness and concern worldwide. ${ }^{11}$ In Nepal, Isolated pathogen frequency and antimicrobial resistant rates can vary dramatically even within the same nation. ${ }^{12,3,13}$ Therefore, to ensure the appropriate therapy current knowledge of organism that cause UTI and their susceptibility pattern is mandatory.

The aim of this study is to determine the prevalence of urinary tract infection in the patients attending a hospital of Kathmandu valley and find out the etiologic agents and their antibiotic susceptibility pattern.

\section{MATERIALS AND METHODS}

A descriptive and cross sectional study was conducted at the department of microbiology in A \& B hospital Lalitpur, Nepal in between April 2010 to March 2011. Samples were collected from the clinically suspected patients before the start of antibiotic therapy. Samples from the patients who diagnosed clinically of UTIs and on antibiotic therapy were excluded.

The collected samples were examined microscopically. They were preceded immediately, but delayed ones were refrigerated at $4^{\circ} \mathrm{C}$ until processing. Ten milliliters of urine sample was taken in a clean sterile centrifuge tube, and centrifuged at $3000 \mathrm{rpm}$ for 10 minutes. The supernatant was discarded aseptically and the sediment in the centrifuge tube was homogenized in 1001. Then sediment was examined by wet preparation and Gram stained.

A loopful of homogenized urine sediment was taken with a standard loop (4 $\mathrm{mm}$ diameter) on a new clean sterile glass slide and spread in an area of $1.5 \mathrm{~cm} \times 1.5 \mathrm{~cm}$. Gram staining of urine sediment was performed ${ }^{14}$ and the number of organisms was counted in each oil immersion field. The urine samples were applied to a glass microscope slide, allowed to air dry, stained with gram stain, and examined microscopically. Bacterial isolates were identified with their general characteristics as motility, shape, stains, biochemical tests and serotyping as needed. ${ }^{15}$

Culture of each uncentrifuged urine specimen was done quantitatively on 5\% Blood Agar and Mac Conkey agar (Oxoid, Unipath Ltd., Basingstoke, England) plates. An inoculating loop of standard dimension was used to take up approximately fixed and a known volume $(0.001 \mathrm{ml})$ of mixed uncentrifuged urine. After incubating the plates aerobically at $37^{\circ} \mathrm{C}$ for 24 hours, colonies were counted. Cultures were interpreted as positive, negative, non-significant or mixed for UTI according to the standard criteria endorsed by the American Society for Microbiology based on the colony count, the urine analysis findings and patient-specific clinical symptoms as provided on the request slip. ${ }^{16}$

Identification of significant isolates was done by using standard microbiological techniques as described which involves the morphological appearance of the colonies, staining reactions, biochemical properties and serotyping if required in specific cases. ${ }^{14,15}$ All isolates were tested for susceptibility to antimicrobial agents on Muller- Hinton agar by Kirby Bauer disc diffusion method recommended by NCCLS. ${ }^{17}$

The paper discs of selected antibiotics were gently pressed onto the organism-carpeted plate at a distance of $15 \mathrm{~mm}$ away from the edge and $24 \mathrm{~mm}$ apart from each other. After incubation at $37^{\circ} \mathrm{C}$ for 24 hour the diameter of the zone of bacterial growth inhibition around each disc was measured and the susceptibility or resistance to the agent in each disc was determined according to the standard Zone of inhibition with specific concentration provided by the manufacturer. Data were entered into Microsoft Excel and analyzed.

\section{RESULTS}

Out of 1,260 specimens examined in this study, 25.24\% showed significant bacteriuria; majority $61.64 \%$ were female and $38.36 \%$ were male (Table 1 ). 
Age and sex wise prevalence of UTI (Table 2) indicate that the highest percentage of organisms was isolated from both male and female within the age brackets of 20-30 years and $30-40$ years respectively. Comparatively in all age groups, female were more frequently affected than males.

Of the 318 isolates, more than half of the cases $(66.67 \%)$ were reported as E. coli followed to Enterococcus and Staphylococcus with prevalence $24(7.55 \%)$ and $21(6.60 \%)$ respectively. The rate of isolates of E coli and Staphylococcus were higher in isolates exclusively from females (Table 3).

The in-vitro antibiotic sensitivity pattern of the isolates to common anti-microbial agent is shown in Table 4. Results indicated that incidence of drug resistant among the positive cases like the highest resistant of positive cases with Cefexime (87.88\%) and Enterococcus with Ampicillin (66.67\%), Staphylococcus aureus with Cloxacillin $(66.67 \%)$. The highest susceptibility was for Vancomycin and Ampicillin i.e. $33.33 \%$ in each. The susceptibility for Penicillin, Erythromycin and Cloxaxillin was same i.e., $25 \%$ in each drug. The least susceptibility was found in Ciprofloxacin, Ofloxacin, Ceftriaxone and Amoxicilin showed $10 \%$ susceptibility in each drug case.

\section{DISCUSSION}

This study shows the distribution and antimicrobial drugs susceptibility pattern of bacterial species isolated from patients with UTI in the laboratory of B\&B Hospital of Lalitpur, Nepal. Out of 1260 urine samples, 318 (25.24\%) samples showed the growth of significant bacteriuria. Previous studies also reported low prevalence of UTI., , 10,18 $^{2}$ Low positivity might be due to the urine samples obtained

\begin{tabular}{lccc}
\multicolumn{4}{l}{ Table 1: Gender wise Prevalence of UTI } \\
\hline Sex & Total examined & Positive & Prevalence (\%) \\
\hline Male & 550 & 122 & 38.36 \\
Female & 710 & 196 & 61.64 \\
Total & 1260 & 318 & 25.24 \\
\hline
\end{tabular}

from the patients from under treatment cases. The slow growing organisms and infection from them cannot able to grow on the routinely used media.

The prevalence of UTI in the population was $25.24 \%$. This figure is higher than prevalence rate (4.6) significant bacterium recorded. ${ }^{19}$ It is lower than the prevalence rate of $37.3 \%{ }^{20}$ and similar prevalence $(26 \%)$ with a study done in Kathmandu valley ${ }^{18}$ and Bharatpur hospital of Chitwan district of Nepal. ${ }^{21}$ The high prevalence may be due to population susceptibility influenced by factors like sexual intercourse, peer group influence, pregnancy, and low socio-economic status.

In this study, the prevalence of UTI in female is more than in males. Of the 1,260 isolates obtained, $122(38.36 \%)$ were from male patients while $196(61.64 \%)$ were from female. This reports that UTI is more frequent in female than in male. Previous studies also reported the similar findings. Kolawole et al reported the higher prevalence rate of UTI in females than males. ${ }^{4}$ The prevalence rate in female (66.67\%) and male (33.33\%) and in a hospital based study in Pokhara, Nepal. ${ }^{3}$ Acharya et al also reported the higher prevalence rate in females than male in Bharatpur Nepal. ${ }^{21}$ The higher incidence of UTI among the females is related to their anatomical and physiological relationship. This is as a result of shorter and wider urethra. The anatomical relationship of the female's urethra and the vagina makes it liable to trauma during sexual intercourse as well as bacteria been massaged up to urethra into the bladder during pregnancy and child birth. $^{4,22}$

We found the different cultural positive results of UTI among the sexes by ages. The more susceptible age group among the male was 20-30 years and while in females 30-40 years followed to 20-30 years. This clearly indicates that sexually active young women are found to be suffering highly from UTI than other age groups. Other study findings also reported that females with age groups $33 \pm 14.5$ were found to be more susceptible to UTI. ${ }^{3,13}$

Table 2: Prevalence of UTI in relation to age and sex

\begin{tabular}{lccccc}
\hline Age group (yrs) & $\begin{array}{c}\text { Male } \\
\text { Examined }\end{array}$ & $\begin{array}{c}\text { Male } \\
\text { Positive (\%) }\end{array}$ & $\begin{array}{c}\text { Female } \\
\text { Examined }\end{array}$ & $\begin{array}{c}\text { Female } \\
\text { Positive (\%) }\end{array}$ & $\begin{array}{c}\text { Total } \\
\text { Positive (\%) }\end{array}$ \\
\hline $0-10$ & 25 & $3(12)$ & 43 & $13(30.23)$ & $16(42.23)$ \\
$10-20$ & 41 & $10(24.39)$ & 48 & $12(25)$ & $22(49.39)$ \\
$20-30$ & 123 & $28(22.76)$ & 119 & $45(37.81)$ & $73(30.16)$ \\
$30-40$ & 72 & $14(19.44)$ & 207 & $48(23.19)$ & $62(42.63)$ \\
$40-50$ & 79 & $14(17.72)$ & 105 & $25(23.81)$ & $39(41.53)$ \\
$50-60$ & 67 & $18(26.86)$ & 81 & $22(27.16)$ & $40(54.02)$ \\
$60-70$ & 67 & $10(14.92)$ & 52 & $9(25)$ & $23(39.92)$ \\
$70-80$ & 53 & $18(33.96)$ & 35 & $9(25.71)$ & $27(59.67)$ \\
80 \& over & 23 & $7(30.43)$ & 20 & $196(27.60)$ & $318(75.43)$ \\
Total & 550 & $122(22.18)$ & 710 & & \\
\hline
\end{tabular}




\section{Table 3: Frequency of isolation in relation to sex of patients}

\begin{tabular}{|c|c|c|c|}
\hline Organisms & $\begin{array}{c}\text { Isolates from } \\
\text { males }\end{array}$ & $\begin{array}{l}\text { Isolates from } \\
\text { females }\end{array}$ & Total (\%) \\
\hline Escherichia coli & 72 & 140 & $212(66.67)$ \\
\hline Klebsiella sp. & 7 & 11 & $18(5.66)$ \\
\hline Enterococcus & 14 & 10 & $24(7.55)$ \\
\hline Pseudomonas aeruginosa & 6 & 4 & $10(3.15)$ \\
\hline Acenetobacter & 5 & 2 & $7(2.20)$ \\
\hline Streptococcus faecalis & 4 & 1 & $5(1.57)$ \\
\hline Citrobacter & 0 & 1 & $1(0.31)$ \\
\hline Enterobacter & 7 & 2 & $9(2.83)$ \\
\hline Staphylococcus aureus & 5 & 16 & $21(6.60)$ \\
\hline Yeast cells & 2 & 4 & $6(1.89)$ \\
\hline Total & 122 & 196 & $318(100)$ \\
\hline
\end{tabular}

\begin{tabular}{|c|c|c|c|c|c|c|c|c|c|c|c|c|c|c|c|c|c|}
\hline \multirow[t]{2}{*}{ Microorganism } & \multirow[t]{2}{*}{ No.tested } & \multicolumn{16}{|c|}{ Percentages of sensitive isolates } \\
\hline & & Peni & Ery & Amik & Cotri & Genta & Nitro & Cipro & Oflo & Ceftri & Clox & Cefp & Amox & Norflo & Vanco & Chloro & Impi \\
\hline E. coli & 212 & 16.07 & 11.76 & 36.36 & 68.42 & 49.44 & 48.15 & 55.40 & 67.40 & 69.70 & 13.33 & 87.88 & 71.50 & 85.71 & & 6.67 & \\
\hline Klebsiella sp. & 18 & & & 4.55 & 2.63 & 4.49 & 9.26 & 5.76 & 4.42 & 6.82 & & 6.06 & 8.41 & 4.76 & & 6.67 & \\
\hline Enterococcus & 24 & 42.86 & 47.06 & 25.00 & 15.79 & 22.47 & 1.85 & 17.27 & 11.05 & 8.33 & 13.33 & & 4.67 & & 42.86 & 20.00 & 66.67 \\
\hline Pseudomonas & 10 & & & 4.55 & 7.89 & 3.37 & 9.26 & 5.76 & 3.87 & 3.03 & & & 4.21 & 2.38 & & 20.00 & 16.67 \\
\hline Acenetobacter & 7 & & & 13.64 & 2.63 & 7.87 & 11.11 & 4.32 & 3.31 & 3.79 & & 1.52 & 3.27 & 3.17 & & 6.67 & 16.67 \\
\hline Streptococcus & 5 & 7.14 & 9.80 & 4.55 & & 2.25 & & 3.60 & 2.76 & 3.03 & 6.67 & & 0.93 & & 28.57 & & \\
\hline Proteus mirabilis & 5 & & & & & & 9.26 & 0.72 & 0.55 & 0.76 & & 3.03 & 1.40 & 0.79 & & & \\
\hline Citrobacter & 1 & & & 2.27 & & 1.12 & 1.85 & 0.72 & 0.55 & 0.76 & & 1.52 & 0.47 & 0.79 & & & \\
\hline Enterobacter & 9 & & & 9.09 & 2.63 & 5.62 & 9.26 & 2.88 & 2.21 & 0.76 & & & 3.27 & 2.38 & & 6.67 & \\
\hline Staphylococcus & 21 & 33.93 & 31.37 & & & 3.37 & & 3.60 & 3.87 & 3.03 & 66.67 & & 1.87 & & 28.57 & 33.33 & \\
\hline Yeast cells & 6 & & & & & & & & & & & & & & & & \\
\hline $\begin{array}{l}\text { Mean } \\
\text { susceptibility } \\
\text { Index }\end{array}$ & & 25.00 & 25.00 & 12.50 & 16.67 & 11.11 & 12.50 & 10.00 & 10.00 & 10.00 & 25.00 & 20.00 & 10.00 & 14.29 & 33.33 & 14.29 & 33.33 \\
\hline
\end{tabular}

Peni: Penicillin, Ery: Erythromycin, Amik: Amikacin, Cotri: Cotrimoxazole, Genta: Gentamycin, Nitro: Nitrofurantoin, Cipro: Ciprofloxacin, Oflo: Ofloxacin, Ceftri: Ceftriaxone, Cloxa: Cloxacillin, Cefp: Cefepime, Amox: Amoxacillin, Norflo: Norfloxacin, Vanco: Vancomycin, Chloro: Chloroquine, Amp: Ampicillin

The most common organism isolated in these patients was E coli (66.67\%), Enterococcus (7.55\%), Klebsiella sp. (5.66\%), Staphylococcus aureus (6.60\%), and Pseudomonas aeruginosa $(3.15 \%)$. Previous studies found that the commonest invading agent for UTI is E. coli. ${ }^{21,13,23}$ Our study also reported the predominance of E. coli in isolates and accounted for $66.67 \%$ of total bacterial isolates. This higher prevalence of $E$. coli in our study also resemble to the other similar study in context to $\mathrm{Nepal}^{21,18,13,3}$ and abroad too. ${ }^{4,8}$

The most useful antibiotics in this study were amoxacilin, ofloxacin, norfloxacin, ceftriaxone, and ciprofloxacin because they inhibit most commonly isolated UTI pathogens. These drugs are relatively expensive with compared to most antibiotics frequently used resulting the organisms susceptible to it. As found in other studies where similar antibiotics are the most effective. ${ }^{21,23,12}$ Vancomycin, cloxacillin, chloroquine and ampicillin which are commonly used antibiotics were poorly effective against the majority or organisms isolated in this study. This shows that emergence of MDR strain is common in the UTI patients of Kathmandu valley. This might be patients trend to buy the drugs without laboratory investigation, prescription and also do not follow the appropriate dosage and schedule of drugs intake.

\section{CONCLUSION}

Findings of this present study and similar to others may not be representative of the general population because UTI are often treated empirically and susceptibility tests are often carried out when the patient has failed one or more antibiotics. Data used in this study determine the trends of antibacterial susceptibility, to make an antibiotic policy, to compare with national data and for the best choice of clinicians for antibiotic therapy. The results from this study reveal the important infecting organisms found in UTI infection and this is important to increase personal hygiene. Last but not the least, since hospital environment is a place where various pathogenic microorganisms are 
isolated and there is maximum possibility of infection from one to another. Therefore, it is recommended to hospital managements to do everything possible to minimize the spread of these microorganisms to the other patients.

\section{REFERENCES}

1. Morgan MG and McKenzie $\mathrm{H}$. Controversies in the laboratory diagnosis of community acquired urinary tract infection. European Journal of Clinical Microbiology and Infectious Diseases 1993; 12: 491-504.

2. Orrett FA and Davis GK. A comparison of antimicrobial susceptibility profile of urinary pathogens for the years, 1999 and 2003. West Indian Medical Journal 2006; 55(2):95-99.

3. Khadka KS, Khadka J, Lekhak B, Shrestha P and Tiwari BR. Incidence of urinary tract infection among the patients visiting western regional hospital, Pokhara, Nepal. Journal of Health and Allied Sciences 2012;2(1):35-37.

4. Kolawole AS, Kolawole OM, Kandaki-Olukemi YT, Babatunde SK, Durowade KA and Kolawole CF. Prevalence of urinary tract infections (UTI) among patients attending Dalhatu Araf Specialist Hospital, Lafia, Nasarawa State, Nigeria. International Journal of Medicine and Medical Sciences 2009; 1(5):163-167.

5. Aiegoro OA, Igbinosa OO, Ogunmwonyi IN, Odjadjare EE, Igbinosa OE and Okoh Al. Incidence of urinary tract infections (UTI) among children and adolescents in lle-lfe, Nigeria. African Journal of Microbiology Research 2007:13-19.

6. Ronald $A$. The etiology of urinary tract infection: traditional and emerging pathogens. Disease-a-Month 2003; 49(2):71-82.

7. Frank-Peterside $\mathrm{N}$ and Wokoma EC. Prevalence of asymptomatic bacteriuria in students of University of Port Harcourt Demonstration Secondary School. Journal of Applied Sciences and Environmental Management 2009;13(2).

8. Bishara J, Leibovici L, Huminer D, Drucker M, Samra Z, Konisberger $\mathrm{H}$, et al. Five-year prospective study of bacteraemic urinary tract infection in a single institution. European Journal of Clinical Microbiology and Infectious Diseases 1997; 16(8):563-567.

9. Pfaller MA, Jones RN, Doern GV and Kugler K. Bacterial pathogens isolated from patients with bloodstream infection: frequencies of occurrence of antimicrobial susceptibility patterns from SENTRY antimicrobial surveillance program (United States and Canada, 1997). Antimicrobial Agents and Chemotherapy 1998; 42:1762-1770.

10. Karki A, Tiwari BR and Pradhan SB. Study on Bacteria isolated from Urinary tract infection and their sensitivity pattern. Journal of Nepal Medical Association 2004; 43:200-203.

11. Belongia EA and Schwartz B. Strategies for promoting judicious use of antibiotics by doctors and Patients. BMJ 1998;317:668-671.

12. Raza S, Pandey S and Bhatt CP. Microbiological Analysis of the Urine Isolates in Kathmandu Medical College Teaching Hospital, Kathmandu, Nepal. Kathmandu University Medical Journal 2012; 9(4):295-297.

13. Das RN, Chandrashekhar TS, Joshi HS, Gurung M, Shrestha N and Shivananda PG. Frequency and susceptibility profile of pathogens causing urinary tract infections at a tertiary care hospital in western Nepal. Singapore Medical Journal 2006; 47(4):281.

14. Collee JG, Duguid JP, Fraser AG and Marmion BP (eds). In: McCartney practical medical microbiology. $1989 ; 13^{\text {th }}$ ed., Churchill Livingstone, Edinburgh.

15. Cheesbrough M. Medical laboratory manual for tropical countries.Vol-II, Microbiology, 1984; $1^{\text {st }}$ ELBS ed., University Press, Cambridge.

16. Isenberg HD. Clinical microbiology procedures handbook. American Society for Microbiology, Washington, D.C.p, 1993; 1.17.1-1.17.15.

17. Bauer AW, Kirby WMM, Sherris JC and Turch M. Antibiotic susceptibility testing by a standardized single disc method. American Journal of Clinical Pathology 1996; 45:493-499.

18. Kattel HP, Acharya J, Mishra SK, Rijal BP and Pokhrel BM. Bacteriology of urinary tract infection among patients attending Tribhuvan University teaching hospital Kathmandu, Nepal. Journal of Nepal Association for Medical Laboratory Sciences 2008;25-29.

19. Talukder MAS. Sensitivity pattern of positive urine culture in a Teaching Hospital. Bangladesh Renal Journal 1987; 6:49-52.

20. Rai CK, Pokhrel BM and Sharma AP. A prospective study on antibiotic sensitivity profile of the organisms associated with clinical infections among the patients attending TU Teaching Hospital. Journal of Nepal Association of Medical Lab 2001; 3:13-16.

21. Acharya A, Gautam R and Subedee L. Uropathogens and their antimicrobial susceptibility pattern in Bharatpur, Nepal. Nepal Medical College Journal 2011; 13(1): 30-33.

22. Theodore M. Prevalence and antibiogram of urinary tract infection among prison inmates in Nigeria. International Journal of Microbiology 2007; 3: 266-270.

23. Sharma A, Shrestha S, Upadhyay S and Rijal P. Clinical and bacteriological profile of urinary tract infection in children at Nepal Medical College Teaching Hospital. Nepal Medical College Journal 2011; 13(1):24-26. 